\title{
An Empirical Study of Vocational Collage Students' English Learning Strategies
}

\author{
Haiyan Dai
}

\author{
School of Foreign Language, Tianjin University of Science \& Technology Tianjin 300222, China \\ 1010020967@qq.com
}

Keywords: Vocational students; Learning strategies; Language learning strategies

\begin{abstract}
Tianjin Sino-German Vocational Technical College are surveyed to explore students' English learning strategy and the relationship between learning achievement and English learning strategy. The results showed that memory strategy, form practice strategy and cognitive strategy are main strategy of vocational students, while affective strategy, management strategy, functional strategy, social strategy and compensation were ignored by the students. What's more, memory strategy, form strategy, cognitive management strategy keeps positively correlated with their language achievement; Native language strategy, complement strategy keep negatively correlated. The finding not only provides empirical materials for vocational collage education but also enriches the research of English learning strategy.
\end{abstract}

\section{Introduction}

As a global language, English language was instructed in China as a foreign language, which has become a basic subject of students of primary school, middle school, high school students and university. But it wasn't successful as it should be although the students spent much effort and time on English learning [1]. They were not able to use the English language such as listening, speaking, reading and writing effectively. Since learners played passive roles, they were determined what to learn and how the learning well. Therefore, in order to improve educational quality and language level, learners' learning strategy gradually caught scholars' eyesight.

\section{Literature review}

The study of English learning strategies began in the middle of 1970 [1]. Scholars definite and classified the language learning strategies from different theoretical perspectives. Oxford (1990) defined language learning strategies as behaviors or actions which learners used to make language learning more successful. She classified language learning strategies in to direct strategies and indirect strategies. Direct strategies are further divided into memory strategies, cognitive strategies, and compensation strategies; indirect strategies are divided into meta-cognitive strategies, affective strategies and social strategies [2]. This classification was wildly accepted by researchers [3].

Qiufang Wen defined it as measures which taken by L2 learners for the purpose of effective learning. She categorized it as management strategy, formal practice strategy, functional practice strategy and native language strategy [4]. It was widely accepted by Chinese scholars of this field because it considers both the outside and inside actions of learners. What's more, it provided detail understandings about meta-cognitive strategies and take native language into consideration. Therefore, the present study takes Oxford's and Wen's classifications as theory orientation to serve a further investigation on the learning strategies of vocational students.

\section{Methodology}

\subsection{Research questions.}

1.What are the main strategies used by the vocational collage students. 
2. What is the relationship between students' English learning strategies and learning achievement?

\subsection{Instruments.}

Quantitative research is powerful and popular method accepted used in previous studies [3]. Aims at exploring students' language strategies and the relationship between students' English learning strategies and learning achievement in China, questionnaire is designed for data collection. Nine categories of learning strategies were adopted which including Wen's management strategy, formal strategy, functional strategy native language strategy and Oxford's memory strategy, cognitive strategy, compensation strategy, affective strategy and social strategy. The questionnaire includes 84 items and the subjects are asked to choose the proper answer among five Liken-scales response for each strategy described. What's more, date back interview is adopted to make an in-depth understanding. Semi-interview scale was designed according to the result of described analysis. It encourages the participants to describe their own thoughts, opinions or experiences.

\subsection{Data collection and Analysis.}

Data collection was constructed among 238 questionnaires were distributed, and 221 were collected 216 vocational collage students of Tianjin Sino-German Vocational Technical College as participant. The valid return rate is $90.08 \%$. Among them, 111 are juniors and 105 are seniors. The subjects have learned English for several years and had stable learning strategies.

Students' English achievement is reflected by the examination [6]. Therefore, students' scores of final examination were adopted for the purpose of exploring the relationship between learners' learning strategies and learning achievements.

The data were processed and analyzed with the help of software SPSS 17.0. The data analysis was conducted in two steps according to the two research questions. First, descriptive Statistics (mean score and standard deviation) was stated to give detailed information about the overall strategy of vocational students. Second, the Pearson Correlation Coefficient was used to explore the correlation between learners' learning strategies and their English learning achievement.

\section{Results}

\subsection{English learning strategy of vocational students.}

The overall learning strategy of the vocational collage students is displayed in table 1 .

Table1: the strategies used situation among those students

\begin{tabular}{|c|c|c|c|}
\hline \multirow{2}{*}{ Learning Strategies } & \multicolumn{3}{|c|}{ Strategy Level } \\
\cline { 2 - 4 } & $\mathrm{X}$ & Stan,D & Level \\
\hline Memory strategy & 3.94 & 0.73 & High \\
\hline Formal strategy & 3.79 & 0.55 & High \\
\hline Cognitive strategy & 3.74 & 0.63 & High \\
\hline Native language strategy & 3.69 & 0.69 & high \\
\hline Affective strategy & 3.56 & 0.46 & Moderate \\
\hline Social strategy & 3.39 & 0.46 & Moderate \\
\hline Functional strategy & 3.22 & 0.71 & Moderate \\
\hline Management strategy & 3.18 & 0.66 & Moderate \\
\hline Compensation strategy & 3.18 & 0.62 & Moderate \\
\hline Overall & 3.49 & 0.61 & Moderate \\
\hline
\end{tabular}


According to Table 1, vocational students take such a wide use of English learning strategies. They adopted memory strategy, formal strategy, cognitive strategy, native language strategy, affective strategy, management strategy, functional strategy, social strategy and compensation strategy, in overall, was in "Moderate" level $(X=3.49$ and $S . D=0.61)$. Specifically, the memory learning strategy, formal strategy, cognitive language strategy and the native language strategy in overall were in "High" level. It reveals that vocational students learning English main depend on memory and reciting and they focused on the form of language. Meanwhile, they tend to enhance their English proficiency by the help of native language. This founding was verified by date back interview. Some of the students reported reciting the vocabulary and sentence is their best way to improve English.

What's more, affective strategy, social strategy, functional strategy, management strategy and compensation strategy, in overall, was in "Moderate" level. Especially the management strategy and compensation strategy lies the lowest level of average value, which reveals that the vocational students adopt those strategies in low frequency. It means that the students use those strategies maybe ignore the function of social communication at the beginning of their foreign language learning. Therefore they obtain a foreign language tend to based on a single and rigid way, which lead to a result of hard-working but gained little. Just as the students expressed "We have no detail plans for their language learning and dislike to discuss with others." The probable reason is their low proficiency and affection of language.

\subsection{The relationship between learning strategies and learning achievement.}

The relationship between English learning strategies and language examination scores was analyzed by Pearson Correlation Coefficient analysis method ( $\mathrm{p}<0.05)$. Results can be seen in table 2

Table2: Relationship between English learning strategies \& language achievement

\begin{tabular}{|c|c|c|}
\hline & Pearson correlation & Significant level \\
\hline Memory strategy & .814 & .000 \\
\hline Formal strategy & .731 & .000 \\
\hline Cognitive strategy & .636 & .001 \\
\hline Native language strategy & -.121 & .000 \\
\hline Affective strategy & .213 & .000 \\
\hline Management strategy & .478 & .000 \\
\hline Functional strategy & .405 & .000 \\
\hline Social strategy & .420 & .000 \\
\hline Compensation strategy & -.095 & .003 \\
\hline
\end{tabular}

The table 2 shows that there exists correlation between English learning strategies and learning achievement among vocational students. Firstly, there were significant positive correlations between memory strategy, formal strategy, functional strategy, affective strategy, social strategy, compensation strategy and English examination scores. That is to say, the learners who with high scores in the English examination are always use those strategies and much more frequently than those lower ones. Secondly, there was a significant negative correlation between native language strategy, compensation strategy and their scores. It means that the students who use native language strategy, compensation strategy frequently with lower scores in the final examination.

\section{Discussions}

The conclusion can be draw according to the data analysis. Firstly, memory strategy and formal strategy are well used by vocational collage students. According to Wen Qiufang (1993), successive language learners tend to adopt functional strategy instead of formal strategy. But comparing the data of the two strategies, the researcher found that the vocational students use formal strategy more 
frequently than the functional strategy. It shows that students focus the traditional language learning methods such as reciting vocabularies and grammar. What's more, low positive correlation exists among management strategy, social strategy and the students' achievement. It reveals the management and cooperative plays a no obvious role during students' earning. The data back interview reflected that students without any realization of management of learning and they didn't know how to management their study. At last, negative correlation exists between native language strategy and achievement. Students even told that they mark the pronunciations by their mother tong. This finding is consistent with previous research made by Wen (1993). Therefore, it is quite significant to the teachers to help them cultivate the communicative strategies.

\section{Conclusion}

The present study reveals that the nine kinds of strategies are used by vocational collage students. It means, in some degree, that those students totally realized the importance of using strategies during learning a foreign language. What's more, the vocational students, more or less used all the categories of strategies. Vocational collage students tend to rely on the traditional strategies. The memory strategy, formal strategy and native language strategy are the most popular learning strategies among them; while the functional strategy, social strategy and compensation strategy seldom guide student's language learning. Both positive and negative correlations are exists between the strategies and language achievement. According to this research, except for native language strategy, affective strategy, compensation strategy with negative correlation, the others six strategies keep positive correlation with students learning achievement.

Those findings may provide an empirical basis for the vocational collage language education and it is useful for students' effective learning. Meanwhile, the results might limit by the sample size. Due to the time constraints and present research condition, the objects were merely 214 vocational students, and this was a small sample for a survey, so they were not representative enough. Further research of this field can be done by more comprehensive way.

\section{References}

[1] Jindaprasert, A-pa-pon. Development of Foreign Language Learning Strategies. Journal of Research, Khon Kaen University, 2(1) January-June (1997).

[2] Oxford, Rebecca. Language Learning Strategies: What Every Teacher Should Know Boston: Heinle \& Heinle Publishers (1990).

[3] Lan, Rae L. Language Learning Strategies Profiles of EFL Elementary School Students in Taiwan. Abstract from: UMI Proquest Digital Dissertation Item (2005).

[4] Wen, Qiufang.1993. Advanced level English language learning in China: The relationship of modifiable learner variables to learning outcomes. Unpublished Ph.D. thesis, Hong Kong University, New York:Newbury House Publishers, (1990): 27-49.

[5] Kotesombat, Narumon. A Case Study of Usage in English Language Learning Strategies. Master of Art Thesis in Applied Linguistic, Graduate School, Mahidol University (2003). 